\title{
ANALISIS DAN IMPELMENTASI SISTEM INFORMASI SERTIFIKASI DIBIDANG KOMPETENSI DAN PENGELOLAAN KELEMBAGAAN PADA BADAN PENGEMBANGAN SUMBER DAYA MANUSIA PROVINSI KALIMANTAN SELATAN
}

\author{
1) Auliya Rahman \\ ${ }^{2)}$ Ibrahim \\ ${ }^{1)}$ Fakultas Teknologi Informasi, Universitas Islam Kalimantan ( UNISKA ) Banjarmasin \\ Email: auliyarahmankom@gmail.com \\ 2) Fakultas Teknologi Informasi, Universitas Islam Kalimantan ( UNISKA ) Banjarmasin \\ Email: terrasin06@gmail.com
}

\begin{abstract}
ABSTRAK
Di era globalisasi dan pasar yang kompetitif menuntut daya tahan dan daya saing sebuah komunitas, organisasi, instansi dan negara dalam bentuk pengembangan sumber daya manusia menjadi salah satu faktor yang penting dalam mendukung produktivitas dan keunggulan kompetititf dalam sebuah instansi khususnya di pemerintahan provinsi kalimantan selatan. Dalam pengelolaan data sertifikasi juga harus memberikan kemudahan bagi si pemakai, karena sebelumnya masih menggunakan sistem konvensional atau manual sehingga menghambat proses data dan laporan yang diperlukan sangat lambat. Dalam hal ini dibangun sebuah sistem berbasis web PHP dan database mysql agar semua data bisa terelasi dan terkomputerisasi dengan baik dan membantu dalam pengambilan sebuah keputusan yang mana laporan atau informasi dihasilkan bisa cepat dan akurat.
\end{abstract}

Kata kunci : Sertifikasi, Sumber Daya Manusia, PHP, Mysql

\section{PENDAHULUAN}

Perkembangan teknologi dalam kurun waktu singat telah mengalami perkembangan yang sangat pesat. Teknologi pada dasarnya dibuat dan kembangkan oleh manusia untuk mempermudah setiap pekerjaan dan urusan. Salah satu cara meningkatkan kinerja serta keprofesionalan dari pegawai adalah dengan adanya pendidikan dan latihan (Diklat). Pendidikan dan pelatihan (Diklat) merupakan salah satu bentuk kegiatan dari program pengembangan sumber daya manusia (personal development) yang strategis karena program diklat selalu berkaitan dengan masalah nilai, norma, dan perilaku individu dan kelompok. Program diklat selalu direncanakan untuk tujuan-tujuan, seperti pengembangan pribadi, pengembangan profesionalisme, pemecahan masalah, tindakan yang remidial, motivasi, meninggkatkan mobilitas, dan keamanan anggota organisasi.

Sertifikasi merupakan penetapan yang diberikan oleh suatu organisasi profesional terhadap seseorang untuk menunjukkan bahwa orang tersebut mampu untuk melakukan sesuatu pekerjaan atau tugas spesifik.

Sebuah aplikasi yang baik tentunya sangat membantu peserta dalam mendapatkan informasi. Salah satunya adalah pembuatan aplikasi pendaftaran sertifikasi berbasis web, sistem ini akan menampilkan informasi mengenai hal-hal yang sesuai dengan apa yang dikehendaki. Sebuah aplikasi yang baik tentunya mampu menjalankan semua hal yang berkaitan dengan penyelenggaraan hal-hal spesifik. Semua komponen dipermudah dengan adanya sistem ini. Untuk membuat sebuah program aplikasi yang baik, pengolahan data merupakan kunci utama untuk mencapai kesempurnaan. Dengan pengolahan data yang baik maka kita dapat dengan mudah mengakses data yang dibutuhkan.

Maka dari itu keberadaan aplikasi berbasis web ini sangatlah penting. Karena dengan adanya aplikasi ini maka instansi daerah ini dapat memberikan informasi yang baik kepada pegawai maupun orang lain. Aplikasi ini bertujuan untuk menyajikan informasi yang berkaitan dengan data instansi, sertifikasi, kelembagaan dan pengembangan ketenangan, serta pengelolaan sumber belajar dan 
kerjasama pada bidang tersebut. Sebagai contoh dengan adanya sistem informasi berbasis web pada Badan Pengembangan Sertifikasi Kompetensi dan Pengelolaan Kelembagaan ini sebagai sarana informasi bagi pegawai maupun pihak terkait mengenai informasi-informasi dengan memanfaatkan sistem komputerisasi yang diolah dengan menggunakan bahasa pemrograman web PHP serta database MySQL.

\section{METODE PENELITIAN}

Pada prinsipnya prosedur kerja masih sama, tapi hanya merubah kedalam komputerisasi dengan menggunakan pemprograman $P H P$ dan database $M y s q l$, yang akan memberikan kemudahkan dalam pendaftaran data sertifikasi.

Perancangan sistem yang di lakukan untuk memberikan gambaran umum tentang sistem yang di kembangkan atau yang dirubah menjadi sistem yang baru kepada admin atau user. Tahapan sistem mempunyai 2 tujuan utama yaitu:

1. Untuk memenuhi kebutuhan kepada pemakai sistem.

2. Untuk memberikan gambaran yang jelas dan rancangan yang lengkap kepada user. Dalam sistem yang akan di buat terdapat tahap-tahap yang di lakukan agar dalam pembuatan sistem yang baru lebih terarah dan lebih terurut, sehingga apabila sistem yang telah jadi dan ada kesalahan dapat di temukan dan di perbaiki dengan mudah.

Proses yang dapat dikerjakan oleh pembangun sistem Aplikasi Sertifikasi meliputi, Data Jenis Sertifikasi, Data Program, Data Pengelola, Data Pendaftar, Data Kualifikasi Pendaftar Sertifikasi, Data Pemilik/Penerima Sertifikasi.

Dalam teknik pengumpulan data menggunakan observasi yaitu teknik pengumpulan data yang dilakukan langsung ditempat yang dijadikan objek penelitian diantaranya dengan mengunakan catatan informasi hingga terbentuk catatan bersifat pada masalah yang bersangkutan dan juga teknik dokumentasi yang mencari data-data yang sudah ada dan perlu di kembangkan lagi.

\section{HASIL DAN PEMBAHASAN}

Sistem informasi sertifikasi dibidang kompetensi dan pengelolaan kelembagaan pada badan pengembangan sumber daya manusia provinsi kalimantan selatan berbasis web ini dalam pengimplementasian membutuhkan beberapa tahapan untuk bisa digunakan dalam sebuah sistem informasi. Mulai dari pembuatan Login kemudian dilanjutkan dengan pembuatan form-form lainnya, data yang terhubung dengan database yang sudah dibuat sebelumnya, Berikut tampilan antar muka sistem, sebagai berikut :

1. Form Login Admin

Form Login ini adalah form untuk admin untuk membuka menu utama admin yang ada di menu halaman utama admin dengan mengisi Username dan Password.

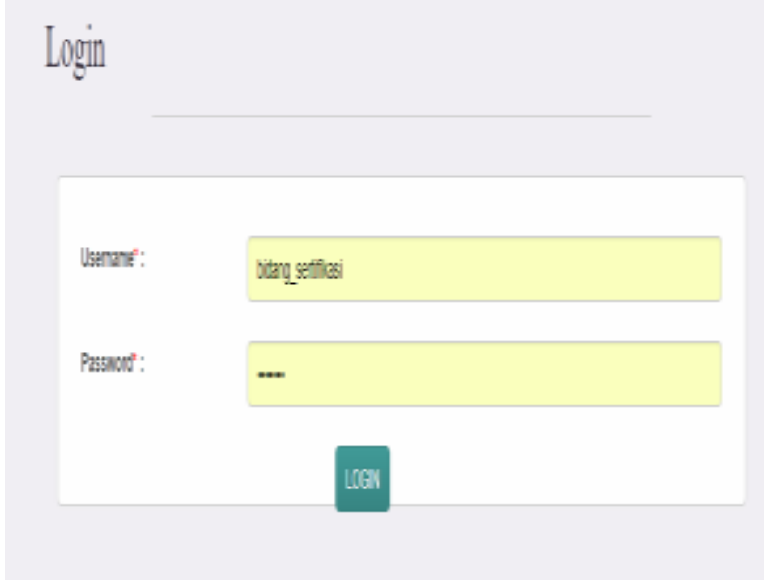

Gambar 1. Form Login Admin

\section{Menu Utama Admin}

Form menu utama admin adalah form ketika sudah masuk login berhasil, form menu ini admin saja yang dapat menginput data untuk data yang ada di halaman utama menu pendaftar/peserta. Jika halaman admin di Logout maka akan muncul halaman utama pendaftar/peserta.

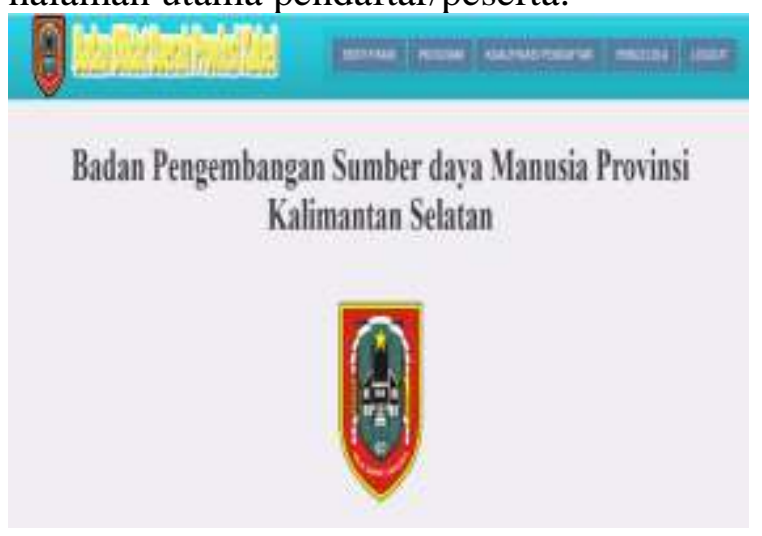

Gambar 2. Form Utama Admin 


\section{Menu Utama Pendaftar Sertifikasi}

Form Utama Pendaftar ini berisikan profil bidang yang dilengkapi sub menu visi dan misi serta struktur organisasi, layanan yang dilengkapi sub menu pendaftaran sertifikasi serta data pendaftar sertifikasi, informasi adalah dimana inputan data dari admin masuk menjadi informasi yaitu Jenis sertifikasi, program diklat, serta data yang sudah mengambil/memiliki sertifikasi.

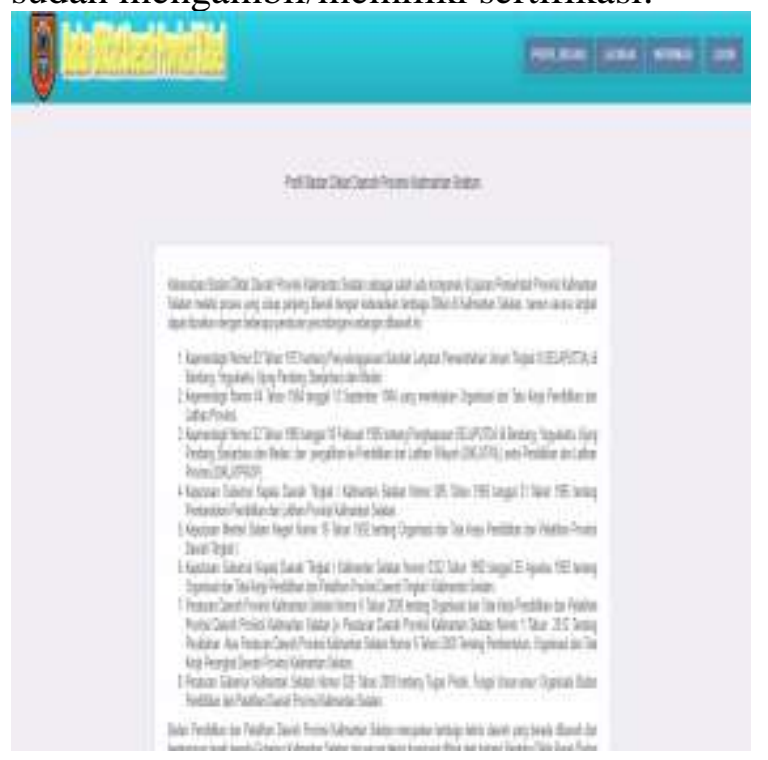

Gambar 3. Form Utama Pendaftar/Peserta

4. Login Pendaftar

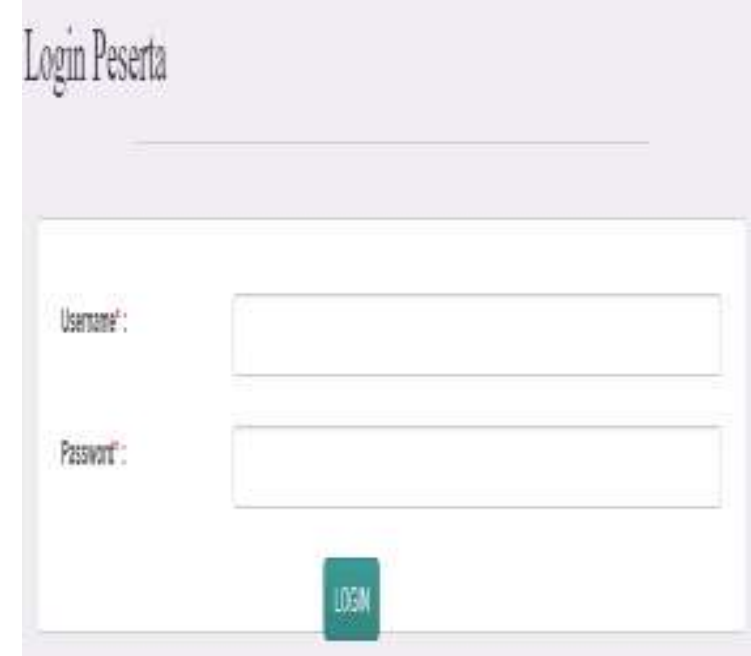

Gambar 4. Login Pendaftar
5. Form Jenis Sertifikasi

Form ini adalah untuk admin menginput data jenis sertifikasi.

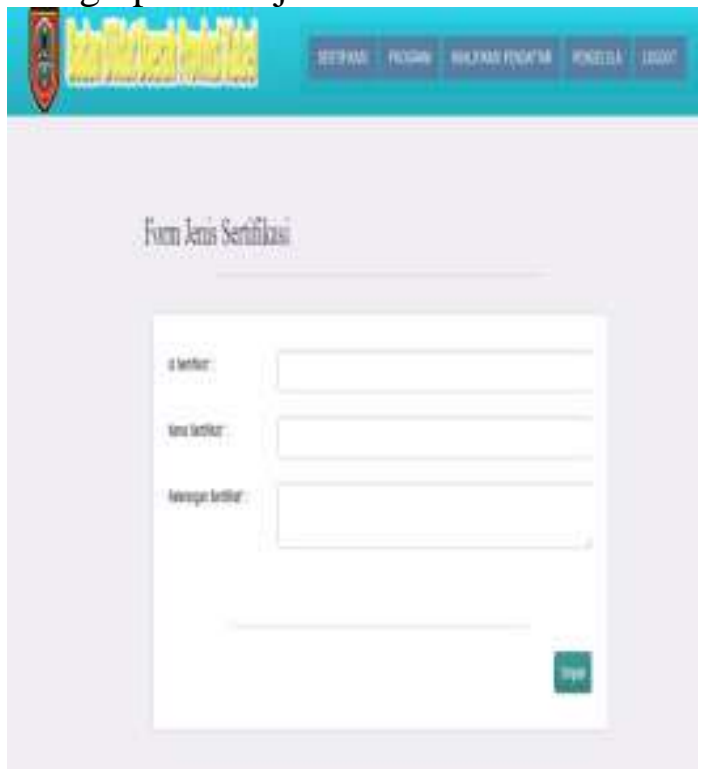

\section{Gambar 5. Form Data Jenis Sertifikasi}

6. Form Program

Form ini untuk admin menginput Program Diklat yang ada, sesuai dengan pendaftar sertifikasi yang sudah mengikuti kegiatan kediklatan tersebut.
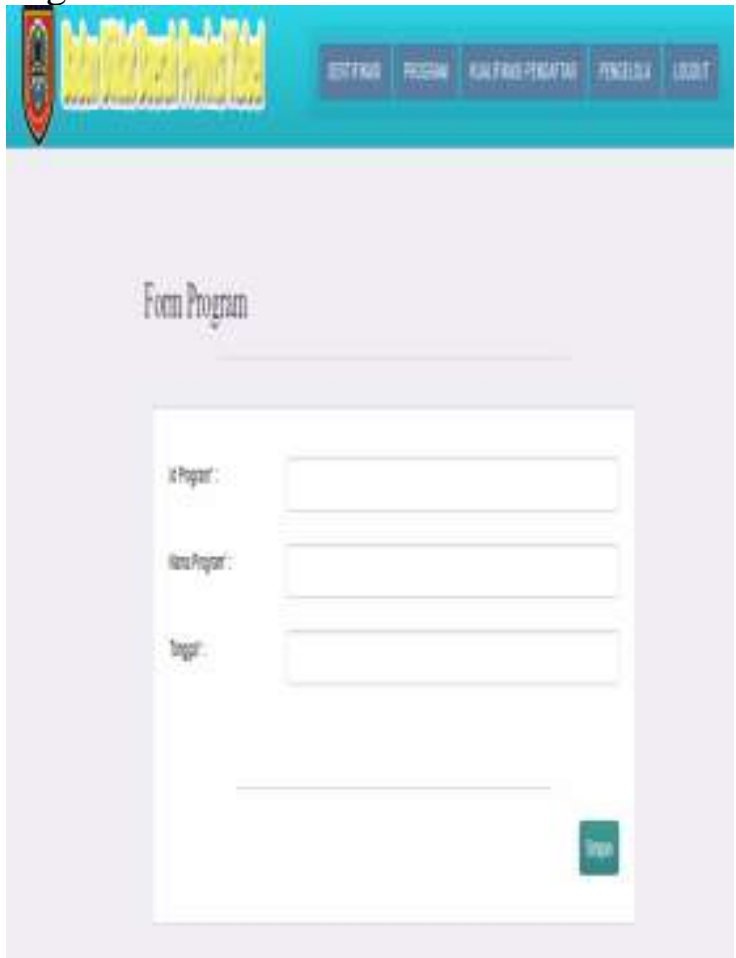

Gambar 6. Form Data Program 
9. Laporan Jenis Sertifikasi

7. Form Pegawai Pengelola Sertifikasi Form ini adalah untuk menginput data pegawai pengelola sertifikasi.

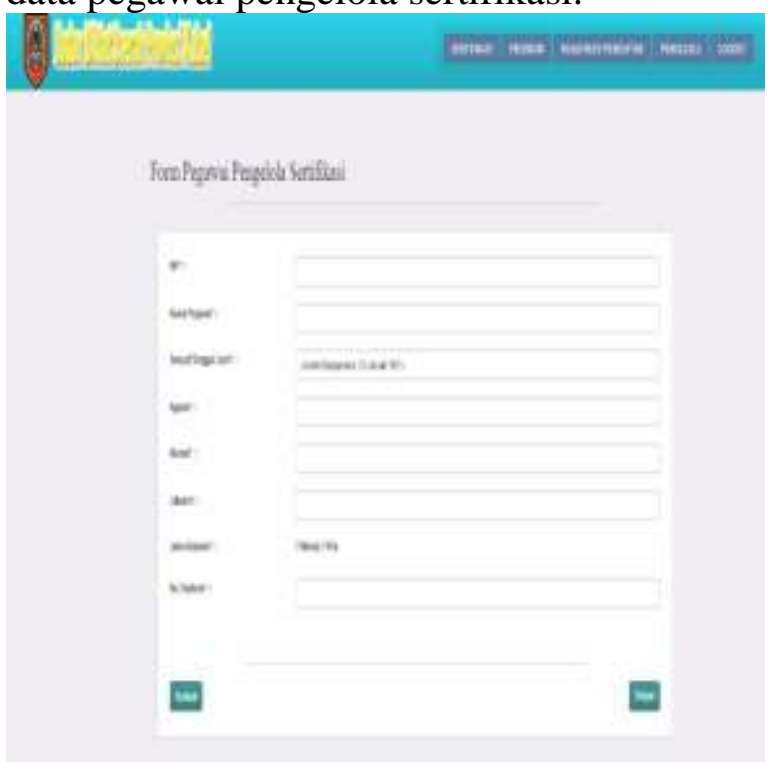

\section{Gambar 7. Form Data Pegawai Pengelola}

\begin{tabular}{|c|c|c|}
\hline Winfit & laiginflat & idfupantility \\
\hline 1 & Stibopatur & 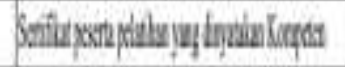 \\
\hline ! & bulkere & 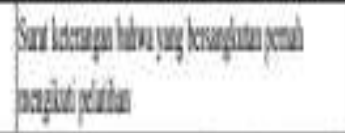 \\
\hline i & Snilibiness & 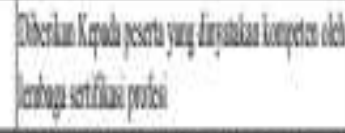 \\
\hline 1 & 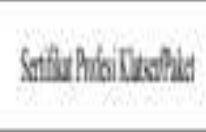 & 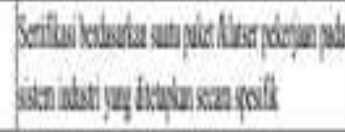 \\
\hline i & bofinhtivisar & 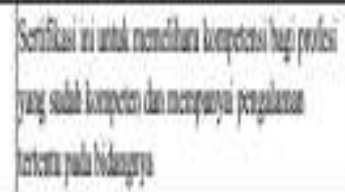 \\
\hline
\end{tabular}

Gambar 9. Laporan Jenis Sertifikasi

8. Form Pendaftar Sertifikasi

Form ini adalah untuk menginput data pendaftar sertifikasi.

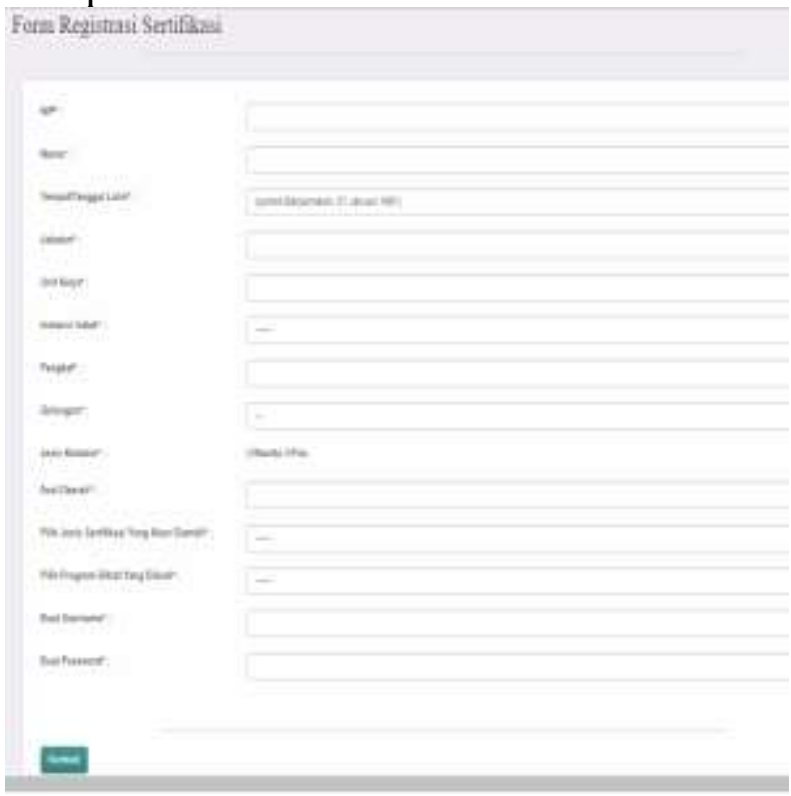

Gambar 8. Form Data Pendaftar Sertifikasi

10. Laporan Program

Ini adalah Laporan Program Diklat yang diikuti pendaftar Sertifikasi.

$$
\text { Dati Plogendm }
$$

\begin{tabular}{|c|c|c|}
\hline IlPngar & Jam họn & Ingullnģı \\
\hline 1111. & Fagion & Wat1:" \\
\hline$m$ & Benementi: & BDeld: \\
\hline $3 x_{212}$ & heteratilial & Ilues:il? \\
\hline HHI & BremenzilI & Mexale WI: \\
\hline 664 & hedrabill & DFenzy III? \\
\hline 367 & Zerminalia & Mexaly:M \\
\hline 361 & Bevenm Milb & QuY: \\
\hline 36 & Benmenstili & Wrew \\
\hline 34ll & Zyeminalit & Shaghts: \\
\hline
\end{tabular}

Gambar 10. Laporan Program 
11. Laporan Pengelola

\section{Data Pengelola Sertifikasi}

\begin{tabular}{|c|c|c|c|c|c|c|c|}
\hline NIP & SanaPregni & $\begin{array}{l}\text { Jarpot hingel } \\
\text { Latir }\end{array}$ & $\operatorname{tg} n$ & Alanit & Intatie & $\begin{array}{c}\text { lanis } \\
\text { Sibarin }\end{array}$ & Mletanx \\
\hline 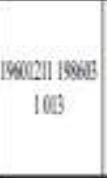 & $\begin{array}{l}\text { BHWWDODX, } \\
\text { SHUIF }\end{array}$ & $\begin{array}{l}\text { Animain: } \\
\text { harilys }\end{array}$ & ins & $\begin{array}{l}\text { Il Watra } \\
\text { Brimbs }\end{array}$ & 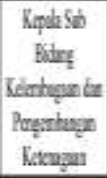 & mi & 6033974 \\
\hline $\begin{array}{c}19851210942 \\
101\end{array}$ & 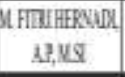 & 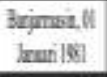 & lin & Al Then & $\begin{array}{l}\text { Sequality } \\
\text { Setionas }\end{array}$ & pil & 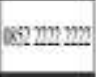 \\
\hline 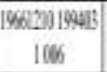 & DAS VAHYIDEX & 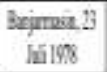 & bin & $\begin{array}{c}\lambda \\
\text { Pethang }\end{array}$ & 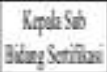 & pil & 10333131342 \\
\hline 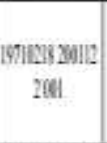 & $\begin{array}{l}\text { HFACLL } \\
\text { WXXah3s }\end{array}$ & $\begin{array}{c}\text { Irtan lijixi } \\
184\end{array}$ & tin & $\begin{array}{c}1 \\
\operatorname{sintax}\end{array}$ & 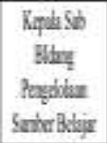 & $\operatorname{vin}$ & W33 $34+4$ \\
\hline 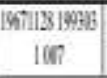 & HUMDUNE, SSSS & $\begin{array}{l}\text { Bajmos } 19 \\
\text { hran } 194\end{array}$ & bin & $\begin{array}{l}\text { I.Nilin } \\
\text { Landan }\end{array}$ & 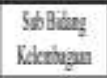 & pit & 683 312646 \\
\hline
\end{tabular}

\section{Gambar 11. Laporan Pengelola}

\section{Laporan Pendaftar Sertifikas}

Data pendaftar sertifikasi, data ini langsung tersimpan pada data kualifikasi pendaftar pada halaman utama admin dan admin akan mengkualifikasi data tersebut.

Badan Pegentengan Sumber Dąa Mansáa Datrah

Provinsi Kalinantan Selatan

Data Pealaftar Sertifiluse

\begin{tabular}{|c|c|c|c|c|c|c|c|c|c|c|c|c|}
\hline D & $\mathbf{X} \mathbb{P}$ & $\mathrm{Kan}$ & 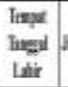 & Shatu & Eithes & $\begin{array}{l}\text { Intasi } \\
\text { late }\end{array}$ & huging & Clocegu & Kand & wal beral & hening & $\begin{array}{l}\text { Menan } \\
\text { Deder }\end{array}$ \\
\hline 91310 & 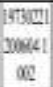 & $\begin{array}{l}\text { DARUS } \\
\text { EAN,S } \\
\text { be }\end{array}$ & 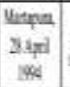 & $\begin{array}{l}\mathrm{bat} \\
\mathrm{mad}\end{array}$ & 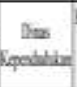 & $\begin{array}{l}\text { Shown } \\
\text { Bina } \\
\mathrm{hal}\end{array}$ & $\frac{\tan \pi}{1}$ & IN & $\mathrm{na}$ & histrape & prias & $\begin{array}{l}\text { hightrofel } \\
\text { Ianll }\end{array}$ \\
\hline frastion. & 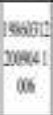 & $\begin{array}{l}\text { DASAL } \\
\text { RAFUAX } \\
\text { 3A4 }\end{array}$ & 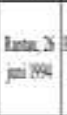 & $\begin{array}{l}\text { Pograr } \\
\text { min }\end{array}$ & Ins & $\begin{array}{l}\text { Silowan } \\
\text { Pla } \\
\text { Soger } \\
\text { linn }\end{array}$ & leygar & Dh & $p$ & Bortiti & int & $\begin{array}{l}\text { highton } \\
\text { beill }\end{array}$ \\
\hline 715ilim! & $\begin{array}{l}\text { Invw: } \\
\text { masB: } \\
06\end{array}$ & 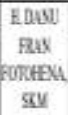 & 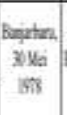 & Parba & Bectan & 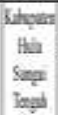 & int.1 & $\mathrm{kis}$ & $\mathrm{pi}$ & Aleptan & $\begin{array}{l}\text { Sonilit } \\
\text { Afians }\end{array}$ & fupound \\
\hline Tresons & 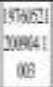 & $\begin{array}{l}\text { IERA } \\
\text { YWEII } \\
\text { GUEESE }\end{array}$ & \begin{tabular}{|c|} 
Rent, \\
Novabe \\
Byt
\end{tabular} & hatis & $\begin{array}{l}\text { lentsit } \\
\text { Imandant }\end{array}$ & $\begin{array}{l}\text { Kibyon } \\
\text { Bitryan }\end{array}$ & $\begin{array}{l}\operatorname{lon} \\
\mathrm{Vad}\end{array}$ & $\mathrm{Hb}$ & $\mathrm{m}$ & $\operatorname{lns} c \mathrm{cts}$ & $\begin{array}{l}\text { Sant } \\
\text { Sarape }\end{array}$ & hisilan \\
\hline מבונד & $\begin{array}{l}\text { IEsch } \\
\text { west? } \\
\alpha e\end{array}$ & $\begin{array}{l}\text { Musti } \\
\text { \$,y }\end{array}$ & 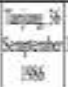 & Pasia & 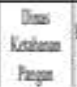 & 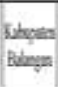 & featre: & ins & wha & Tand & Sorile & $\begin{array}{l}\text { Impoimprx } \\
\text { full }\end{array}$ \\
\hline
\end{tabular}

\section{Gambar 12. Laporan Pendaftar}

\section{Sertifikasi}

\section{Laporan Kualifikasi Pendaftar}

Pada laporan ini data pendaftar akan tersimpan pada data kualifikasi pada admin yang fungsinya jika pendaftar tersebut sudah mendapatkan sertifikat yang diinginkan maka admin mengkualifikasi data tersebut maka data tersebut masuk ke data penerima yang ada pada menu halaman utama pendaftar sebagai Informasi data pemilik sertifikasi.

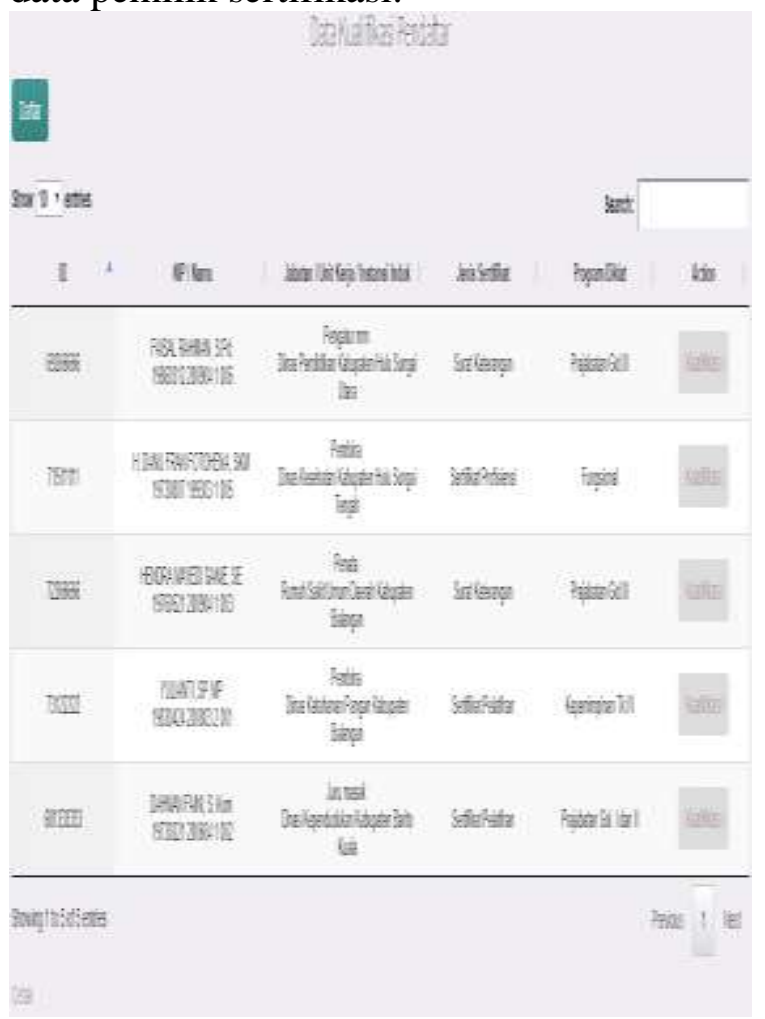

\section{Gambar 13. Laporan yang akan Dikualifkasi}

\section{Laporan Pemilik Sertifikasi}

Pada laporan ini data pendaftar yang sudah dikualifikasi akan otomatis langsung muncul pada informasi yang ada di halaman utama pendaftar sertifikasi sebagai data pemilik sertifikasi. 


\section{Data Yang Sudah Meneriua Sertifilssi}

\begin{tabular}{|c|c|c|c|c|}
\hline ID & $\mathrm{NP} / \mathrm{San}$ & 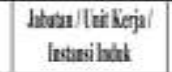 & kesinnifift & Phegn Disat \\
\hline 558 & 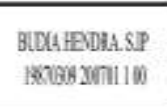 & 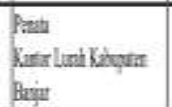 & Setfortulisas & Bquaringea Th Ih \\
\hline $3 x+6$ & 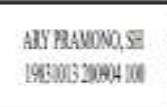 & 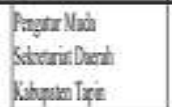 & Sunt Ltangegn & Prigituradill \\
\hline 5444 & 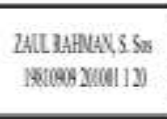 & 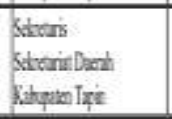 & Sotfletherians & Kenirimin II II \\
\hline $3 x+46$ & 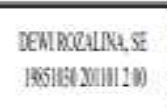 & 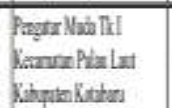 & Strie Krateres & Prigher foll \\
\hline$m$ & 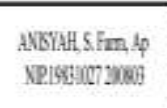 & 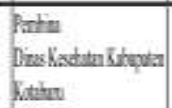 & 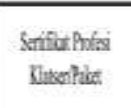 & Kaperimpia Itk \\
\hline
\end{tabular}

$\underline{\text { Kind ini }}$

\section{Gambar 15. Laporan Penerima Sertifikasi}

Jika data sudah dikualifikasi maka data yang ada di data pendaftaran dan data kualifikasi pendaftaran akan otomatis menghilang lalu terpindah ke data penerima sertifikat.

\section{KESIMPULAN}

Kesimpulan aplikasi sertifikasi dibidang kompetensi pengelolaan dan kelembagaan provinsi kalimantan selatan adalah mempermudah pekerjaan dan mempercepat dalam pengumpulan data laporan kepada pimpinan, untuk mempermudah informasi sertifikasi, megakses data pendaftar sertifikasi, meningkatkan bahan pelayanan dan pengelolaan mutu untuk bidang tersebut dan pihak lain yang berhubungan dengan instansi tersebut.

\section{REFERENSI}

Anhar. (2010). Panduan Menguasai PHP \& Mysql. Jakarta: Media Kita.

Abdul Kadir (2013). Pengertian Mysql. Tersedia Dalam : Buku Pintar Programer Pemula PHP. Yogyakarta. Mediakom.
Abdul Kadir (2013). Pengertian PHP. Tersedia Dalam : Buku Pintar Programer Pemula PHP. Yogyakarta. Mediakom.

Mavrody Dan Sergei (2012). HTML5 \& CSS3: Quick Reference. Chicago : Belisso

Syafei,Buyungahmad,P.Hd.2007.

KOMPETEN DAN KOMPETENSI.

Siti Fatmawati (2011). Aplikasi Sistem Informasi Manajemen Logistik Berbasis Web Pada PT Arindo Pratama Cabang Solo. Surakarta: Fakultas Informatika Universitas Muhammadiyah Surakarta.

Virgi, A. H. (2011). CEPAT MAHIR PEMOGRAMAN WEB DENGAN PHP DAN Mysql. Jakarta: PT. Prestasi Pustakaraya. 